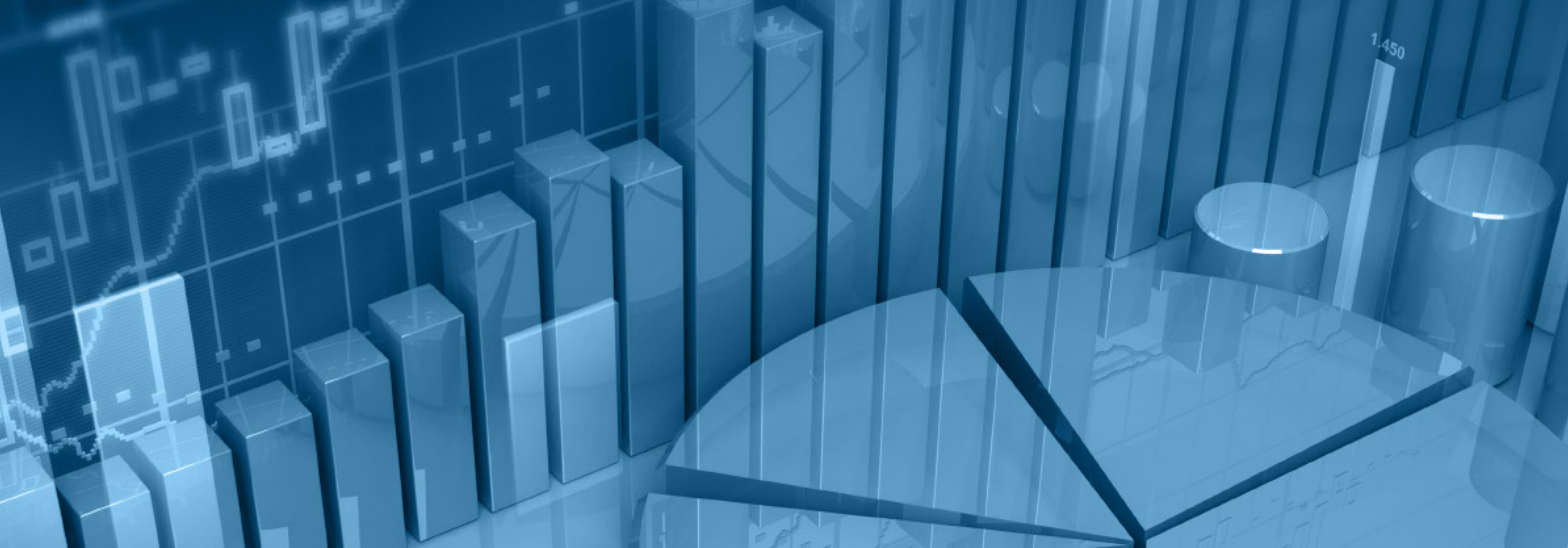

\title{
Understanding Causality: What came first the Chicken or the Egg?
}

\section{By Adrian Fernandez-Perez, Bart Frijns, Alireza Tourani-Rad}

Adrian Fernandez-Perez is a Research Fellow at the Auckland Centre for Financial Research, Auckland University of Technology, New Zealand

Bart Frijns is the Director of the Auckland Centre for Financial Research and Professor of Finance at the Auckland University of Technology, New Zealand

Alireza Tourani-Rad is the Head of Department and Professor of Finance at the Auckland University of Technology, New Zealand

The question of association as opposed to causation is an important issue in many scientific fields, including finance. Much of the empirical research in finance deals with the question of causality or stated differently what came first: the chicken or the egg. We are interested, for example, to know the transmission channels through which shocks propagate themselves in financial markets (e.g., how volatility shocks in one stock market affect other markets); or to build superior forecasting models to find out price leadership among similar financial assets traded on different markets (e.g. is it the shares listed on the home market or the host market of a cross-listed firm that first reacts to a corporate event). Hence, being able to correctly infer the direction of causality among financial assets is crucial for accurately understanding relations among those assets. While in practice we can easily observe correlations among financial assets or markets, detecting causal relationship (in other words, who moves first and who reacts) is often not an easy task.

Think of the following example. Assume that the correlation between the New Zealand and US stock markets is 0.5 . This figure suggests that when a shock occurs to the US market, most of the time the NZ market will move in the same direction as the US market. It also implies that when a shock occurs to the NZ market, most of the time the US market will move in the same direction. While it seems reasonable to assume that the NZ market responds to shocks in the US market, the reverse is less likely. This is, of course, because the correlation is a measure of association and not of causation. If we want to determine the effect of one market on another, we must find a way to identify the direction of causality.

Fortunately, there is a solution to the problem of inferring the direction of causality from correlation coefficients based on a technique known as the "identification through heteroskedasticity" approach originally proposed by Rigobon (2003). Although a full technical description of this technique is beyond the scope of this paper, the approach makes use of non-proportional shifts in the volatility of the assets to break up correlation coefficients into causal relationships among variables. In this article, we will demonstrate the usefulness of this technique by answering the age old question of what came first: the chicken or the egg.

We obtain monthly price data on chickens and eggs from various US websites. Chicken prices (retail price of broiler chickens) are obtained from the website of the United States Department of Agriculture (USDA) (www.ers.usda.gov/datafiles/Meat_Price_Spreads/history. xIs). Likewise, egg prices (Eggs, grade A, large, per doz.) are obtained from the Bureau of Labour Statistics from the United States Department of Labour (http://data.bls.gov/ cgi-bin/srgate). We collect data for the period January 1980 to June 2015. Figure 1 shows price graphs for the two series. Apart from the general upward sloping trend, one can observe some degree of co-movement between the two series. 


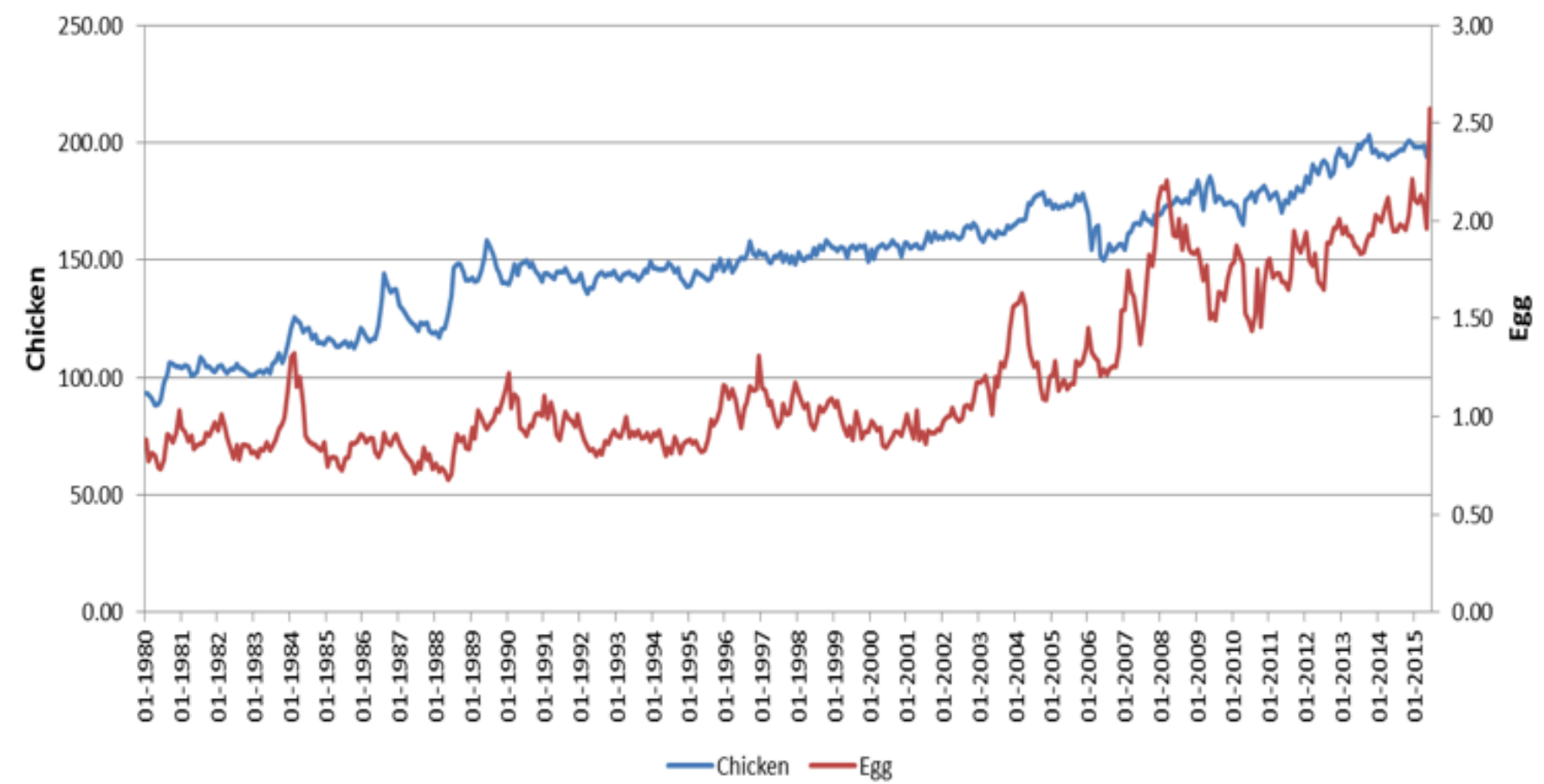

In Table 1, we report summary statistics for the two return series. The positive annualized mean returns confirm the general uptrend pattern observed in Figure 1. We also note that there is much more volatility (standard deviation of about 22\%) in the price of eggs than in the price of chickens. Panel $B$ reports the correlation between the returns of the two series. This correlation of 0.12 is statistically significant, confirming that there is a positive relation between the two return series.

\section{Table 1. Summary Statistics}

\section{Panel A: Descriptive Statistics}

\begin{tabular}{|l|r|r|}
\hline & Chicken & Egg \\
\hline Annual Mean & $2.13 \%$ & $3.03 \%$ \\
\hline Annual Std. Dev. & $7.59 \%$ & $21.69 \%$ \\
\hline Skewness & 0.3486 & 0.1486 \\
\hline Kurtosis & 5.2501 & 3.7867 \\
\hline Observations & 425 & 425 \\
\hline
\end{tabular}

Panel B: Matrix Correlations

\begin{tabular}{|l|c|c|}
\hline & Chicken & Egg \\
\hline Chicken & 1.00 & \\
\hline Egg & $0.12^{* *}$ & 1.00 \\
\hline
\end{tabular}

The traditional way of assessing causality is by looking at who moves first. In academia, we refer to this dynamic causality as Granger causality, which is based on the analysis of looking at how current prices of one series affect the future prices of another series. In Table 2, we document these Granger causality statistics for the returns on chickens and eggs. Although the statistics reported in Table 2 have no direct economic interpretation, we report the $\mathrm{p}$-values of these statistics in italics below the Granger causality statistics. We observe that none of these p-values are below the conventional thresholds for statistical significance (0.05), and thus we can conclude that there is no dynamic causal effect of chicken prices on egg prices or vice versa. So we have two series that are correlated significantly but we find no evidence of causality based on lagged prices, suggesting that the causal interaction between these prices may occur at a higher frequency than the monthly one. One way to extract the direction of causality, when higher frequency data is not available, is the "identification through heteroskedasticity" approach, whereby we are able to break up the correlation into two directional causal effects.

\section{Table 2. Granger Causality Statistics}

\begin{tabular}{|l|r|r|}
\hline \multicolumn{2}{|l|}{ Granger Causality } \\
\hline & Chicken & Egg \\
\hline Chicken & & 3.8847 \\
& & 0.6923 \\
\hline Egg & 6.2142 & \\
\hline
\end{tabular}




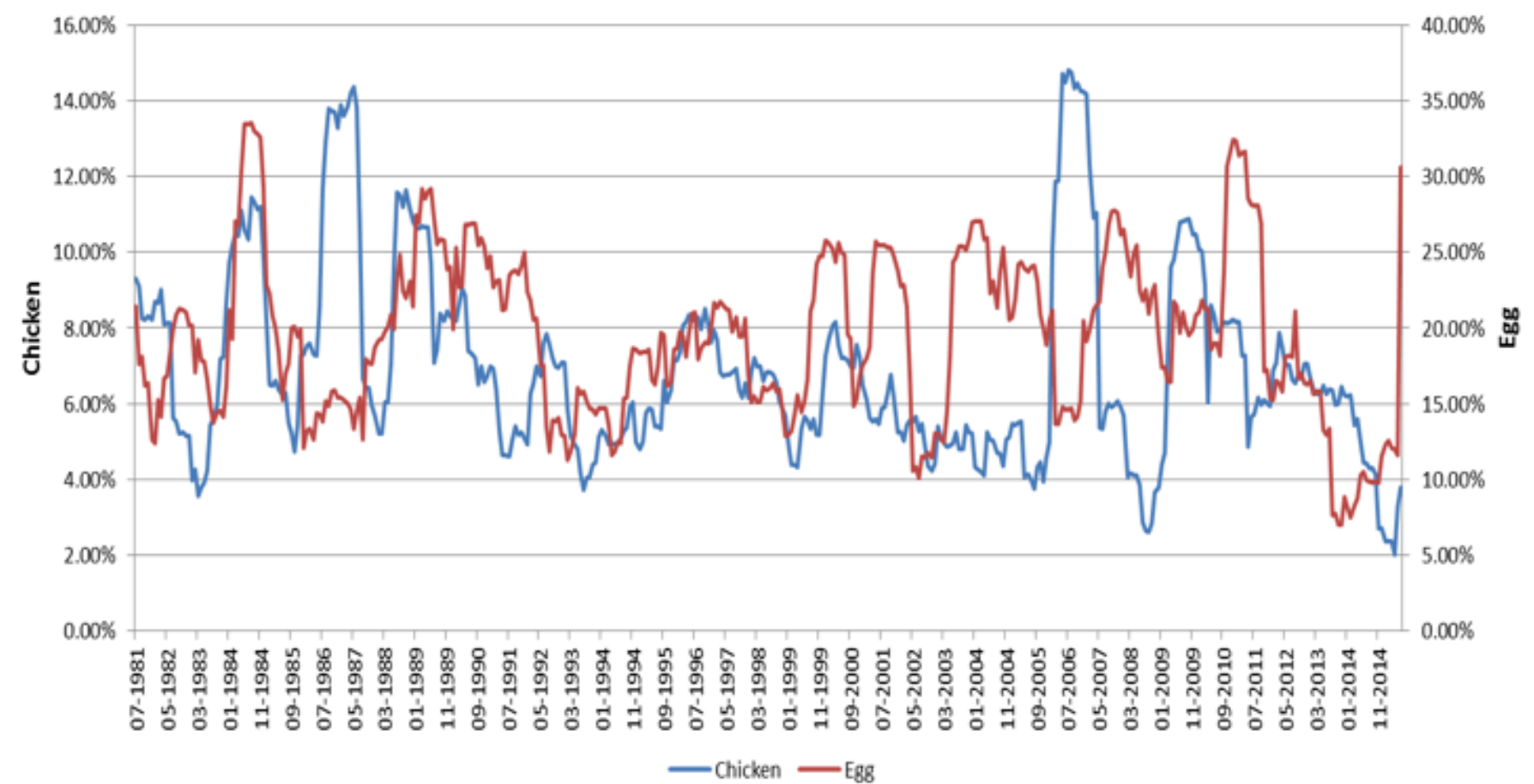

Based on Rigobon's (2003) approach, when there are non-proportional shifts in the volatilities of the two series, we can use those non-proportional shifts to break up the correlation into causal effects. In Figure 2, we plot the volatilities of the two series, which are computed as rolling windows of annual standard deviations. We can clearly observe the non-proportional shifts in the volatility as there are periods when the price of chickens (blue line) is far more volatile than the price of eggs (red line) and periods where the reverse holds true. Since we essentially have two situations (high volatility chickens - low volatility eggs; low volatility chickens - high volatility eggs), we can identify two effects: the effect of shocks in the price of chickens on the price of eggs and vice versa.

In Table 3, we report the results of this analysis, where the first column shows the contemporaneous effect of the price of chickens on the price of eggs and the second column shows the reverse, the effect of the price of eggs on the price of chickens. We can observe that there is a clear and strong effect of the price of chickens on the price of eggs, establishing strong causality from chickens to eggs. The reverse causality is relatively small and insignificant at the conventional $5 \%$ level, suggesting that there is no causal effect of the price of eggs on the price of chickens. Hence, when answering the question of what came first: the chicken or the egg, we can conclude for our analysis that chickens come first and eggs follow... at least when it comes to their prices.

\section{Table 3. Contemporaneous Causality}

\begin{tabular}{|l|r|r|}
\hline \multicolumn{3}{|c|}{ Contemporaneous Causality } \\
\hline & Chicken & Egg \\
\hline Chicken & 1 & $-0.0405^{*}$ \\
& & 0.0670 \\
\hline Egg & $0.6901^{* * *}$ & 1 \\
& 0.0030 & \\
\hline
\end{tabular}

The analysis conducted in this paper demonstrates one of the techniques that are available to infer causality in the case where traditional methods fail. Although the question of what came first: the chicken or egg may be important from an evolutionary point of view, in finance this is perhaps not the most interesting question. However, this technique can easily be extended and applied to situations that are more economically meaningful, for example, in examining the volatility spill-over among different asset classes (Badshah, Frijns and Tourani-Rad, 2013); the direction of volatility spill-over between financial markets when trading hours overlap (Finta, Frijns and Tourani-Rad, 2015), or identifying whether agricultural prices lead or follow biofuel prices (Fernandez-Perez, Frijns and Tourani-Rad, 2015), just to name a few applications. 


\section{References}

Badshah, I., Frijns, B., and Tourani-Rad, A. (2013). Contemporaneous Spill-over among Equity, Gold, and Exchange Rate Implied Volatility Indices. Journal of Futures Markets 33, 555-572.

Fernandez-Perez, A., Frijns, B., and Tourani-Rad, A. (2015). Instantaneous Causality among Fuel, Biofuel and Agricultural Commodities. Working paper.

Finta, M. A., Frijns, B., and Tourani-Rad, A. (2015). Contemporaneous Spillover Effects between the US and the UK. Working paper.

Rigobon, R. (2003). Identification through Heteroskedasticity. Review of Economics and Statistics 85, 777-792.

\section{Corresponding Author:}

Bart Frijns Auckland University of Technology

Department of Finance, Private Bag 92006, Auckland 1142, New Zealand

T: +6499219999 ext. 5706, Email: bfrijns@aut.ac.nz 